Biopsy samples of head and neck carcinomas were investigated with regard to elafin, secretory leukocy te protease inhibitor (SLPI), interleukin 1-receptor antagonist [(IL)1-RA] and soluble tumour necrosis factor $\alpha$ receptor antagonist (STNF $\alpha$ RI). SLPI and elafin are serine protease inhibitors produced in the serous cells of the upper respiratory airways and in the keratinocytes, respectively. We have now found the presence of elafin and SLPI in squamous cell carcinomas of the upper respiratory tract (tonsillar, hypopharyngeal, tongue, mouth floor, gingival and laryngeal cancer). Significantly higher amounts of SLPI and elafin are present in well-differentiated and moderately differentiated tumours than in poorly differentiated tumours $(\boldsymbol{p}<0.0001$ and $\boldsymbol{p}<0.0015)$. Tumour necrosis factor- $\alpha$ and IL- $1 \beta$ have been shown to stimulate the production of SLPI and elafin. Since these cytokines can both be difficult to detect, we chose to study their inhibitors, STNF $\alpha$ RI and IL1-RA, instead. IL1-RA was expressed in highly differentiated tumours as well as in poorly differentiated ones. No significant difference was seen between the groups. STNF $\alpha$ RI was only found in very small amounts, sparsely distributed in the tumours, and was not related to the degree of differentiation.

Key words: SLPI, Elafin, TNF $\alpha$, IL-1 $\beta$, Elastase, Squamous cell carcinomas

\section{The presence of elafin, SLPI, IL1-RA and STNF $\alpha$ RI in head and neck squamous cell carcinomas and their relation to the degree of tumour differentiation}

\author{
U. Westin 1,2,CA, M. Nyström²,3, I. Ljungcrantz ${ }^{2}$, \\ B. Eriksson ${ }^{1}$ and K. Ohlsson ${ }^{2}$
}

${ }^{1}$ Department of Otolaryngology and Head and Neck Surgery, ${ }^{2}$ Department of Surgical Pathophysiology and ${ }^{3}$ Department of Surgery, University Hospital of Malmö, University of Lund, SE-205 02 Malmö, Sweden

\author{
${ }^{\mathrm{CA}}$ Corresponding Author \\ Fax: +4640336240 \\ E-mail: Ulla.Peterson-Westin@oron.mas.lu.se
}

\section{Introduction}

Elafin, or skin-derived anti-leukoprotease, is a $12.3 \mathrm{kDa}$ cationic protein produced by keratinocytes that inhibits human leukocyte elastase and proteinase $3 .^{1,2}$ It has a structural similarity to secretory leukocyte proteinase inhibitor (SLPI), which is another locally produced serine protease inhibitor. $^{3-5}$ SLPI is a potent inhibitor of leukocyte elastase and cathepsin G. ${ }^{6,7}$ Elafin and SLPI differ in inhibiting activity; elafin inhibits proteinase 3, while SLPI exercises an inhibitory effect on cathepsin G. ${ }^{1,8}$ Both SLPI and elafin are produced locally in the lung. ${ }^{9}$ SLPI is also produced in the serous cells of the upper respiratory tract. ${ }^{10,11}$ Elafin is expressed in several epithelia that are continually subjected to inflammatory stimulus; for instance, the oral cavity. Elafin is not found in normal epidermis, but is produced in psoriatic and in hyperproliferative epidermis. ${ }^{1,12}$ Disturbances in proteaseantiprotease balance are common in many disorders such as inflammatory diseases, emphysema and also in cancer. $^{13-17}$ Leukocyte elastase degrades extracellular matrices such as elastin, proteoglycans, collagen and fibronectin, which could enhance tumour invasion by tissue destruction. In addition, increased serum proteolytic activity has been found in patients with advanced colon cancer. ${ }^{18}$ Data from a study of mammary epithelial cells and carcinomas suggest that elafin may be involved in cell cycle regulation. ${ }^{19}$ Elafin can be considered to be a marker for regenerative differentiation. Both elafin and SLPI are potent inhibitors of elastase, which is frequently found in the tumour stroma and tumour cell nests. $^{20,21}$

Tumour necrosis factor- $\alpha$ (TNF- $\alpha$ ) has been found to be a potent inducer of elafin expression at mRNA and protein levels. ${ }^{21}$ Sallenave $e t$ al. have shown that TNF- $\alpha$ and interleukin (IL)-1 $\beta$ both induce SLPI and elafin expression. ${ }^{9}$ Neutrophil elastase has been found to increase cell-associated SLPI. ${ }^{22}$

The aims of the present study were to investigate the expression of SLPI and elafin, and the presence of elastase (i.e. leukocyte invasion) in head and neck squamous cell carcinomas. We also studied the occurrence of TNF- $\alpha$ and IL-1 $\beta$ in these carcinomas since they have been shown to induce elafin and SLPI. 9 The proteinase inhibitors, elastase and cytokines were investigated in relation to the degree of histological differentiation and clinical manifestation of the carcinomas.

Since IL1- $\beta$ and TNF $\alpha$ can be difficult to detect, we chose to study their inhibitors, IL1-RA and STNF $\alpha$ RI. There is an excess of these inhibitors compared with their corresponding protein, which simplifies their detection in tissue. 


\section{Materials and methods}

\section{Tissues}

Archival biopsy material from the Department of Pathology, used for diagnostic histology, was selected. The samples were obtained and embedded less than 1 year before the study. The tissues were fixed in buffered $4 \%$ formalin for $24 \mathrm{~h}$ and then embedded in paraffin. A pathologist classified the head and neck squamous cell carcinomas. A total of 26 tumours from different locations were examined. They were classified as well-differentiated, moderately differentiated or poorly differentiated. The locations of the tumours were the larynx, hypopharynx, gingiva, tongue, floor of the mouth and tonsils. TNM classification was performed at the Ear, Nose and Throat Department, Malmö University Hospital to which the patients had been referred.

The amount of elafin, SLPI, elastase, IL1-RA and STNF $\alpha$ RI in the sections was estimated by staining by a doctor and by a technician on two different occasions each (four times). The amounts were classified as 3, 2, 1 or 0 . The quantifications were in good agreement with each other.

The spreading of the carcinomas to lymph nodes at the time of diagnosis was also noted.

\section{Statistics}

Spearman's correlation coefficient was used to compare the amounts of elafin, SLPI, elastase and IL1-RA in well-differentiated and moderately differentiated carcinomas compared with poorly differentiated carcinomas.

\section{Immunohistochemical staining}

The anti-elafin antibody was tested for cross-reactivity against SLPI at different concentrations using the Ouchterlony immuno-precipitant technique. The same procedure was applied to the anti-SLPI antibody and elafin.

Before staining, sections were deparaffinized with xylene, rehydrated with decreasing concentrations of methanol, and finally rinsed in Tris-buffered saline (TBS) (0.05 M Tris, 0.145 M NaCl; pH 7.6). To quench endogenous peroxidase activity, sections were incubated with $0.3 \% \mathrm{H}_{2} \mathrm{O}_{2}$ in methanol for $30 \mathrm{~min}$ at room temperature, followed by rinsing in TBS for $3 \times 5 \mathrm{~min}$. Slides were then incubated with normal rabbit serum diluted $1 / 20$ to block unspecific staining. SLPI was detected using a goat anti-SLPI antibody (produced at our own laboratory) diluted 1/2000. The slides were then incubated with a biotinylated rabbit anti-goat IgG (Vector Laboratories, Inc., Burlingame, USA) (5 $\mathrm{mg} / 1$ buffer) for $30 \mathrm{~min}$ followed by another $3 \times 5 \mathrm{~min}$ washing in the same buffer, and then incubated with a Vectastain ABC kit (Vector Laboratories, Inc.). After rinsing, substrate reactions were performed by incubation with $0.06 \%$ diaminobenzidine tetrahydrochloride in TBS containing $0.01 \% \mathrm{H}_{2} \mathrm{O}_{2}$ for $5 \mathrm{~min}$. After final rinsing in TBS, sections were counterstained, dehydrated, cleared and mounted. Control sections were incubated with adsorbed antigen or normal goat serum. The sections were counterstained with haematoxylin (Mayer hematoxylin, Histolab., Gothenburg).

To demonstrate the presence of elafin, a primary rabbit anti-human antibody (1/3000) (Peptide Institute, Japan; Scientific Marketing Association, UK) was used. As a secondary antibody, a biotinylated goat antirabbit IgG was applied (Vector Laboratories, Inc.). IL1-RA was detected with a primary rabbit anti-human antibody (1/500-1/1000) (produced at our own laboratory), and a biotinylated goat anti-rabbit IgG was used as the secondary antibody. STNF $\alpha$ RI was visualized with a primary rabbit anti-human antibody (1/500-1/1000) (produced at our own laboratory), and a biotinylated goat anti-rabbit IgG as the secondary antibody, incubated overnight. To visualize elastase, a rabbit anti-human leukocyte elastase antibody was used (1/2000), and a biotinylated goat anti-rabbit IgG antibody was used as a secondary antibody. The procedures were otherwise performed as described for SLPI except for elafin, where the control sections not were subjected to adsorbed antigen since the antibodies were purchased. Control sections in elastase were subjected to a mixture of antigen and antibody.

\section{Results}

No cross-reactivity was observed between anti-elafin antibodies and SLPI, or between anti-SLPI antibodies and elafin.

The classifications 2 and 3 were in agreement in all but three cases. No sections classified as 2 or 3 were classified as 1 or 0 .

\section{Well-differentiated carcinomas}

\section{Elafin}

Elafin was expressed in most squamous tumour cell nests but there were also some cells that did not express the inhibitor. The staining was most prominent in areas with well-differentiated cells. Separate positive tumour cells could be seen located in the tissue in between. Elafin was sporadically expressed in normal squamous epithelium where the carcinoma was not established. Elafin was expressed at all tumour locations examined (larynx, hypopharynx, tonsils, tongue, gingiva and mouth floor) (Fig. 1). The quantity of elafin was significantly higher in welldifferentiated and moderately differentiated carcinomas than in poorly differentiated carcinomas $(\phi<$ 0.0001) (Table 1). 
Table 1. Quantification of elafin, SLPI, elastase and IL1-RA in head and neck carcinomas

\begin{tabular}{|c|c|c|c|c|c|}
\hline Carcinoma & Elafin* & SLPI* & Elastase & IL-1RA & Carcinoma location \\
\hline \multirow[t]{4}{*}{ Well-differentiated } & & 3 & 2 & & Tonsils \\
\hline & 3,3 & 3,2 & 1,3 & 3 & Mouth floor or gingiva \\
\hline & 3,3 & 3,2 & 1,2 & 3 & $\begin{array}{l}\text { Larynx } \\
\text { Hypopharynx }\end{array}$ \\
\hline & 3 & 3 & 3 & 3 & Tongue \\
\hline \multirow[t]{5}{*}{ Moderately differentiated } & $3,1,3$ & 3,1 & $2,3,2$ & 3,3 & Tonsils \\
\hline & 1,1 & 1,0 & & & Mouth floor or gingiva \\
\hline & 2,1 & 3,1 & 1,2 & 3,3 & Larynx \\
\hline & 0,2 & 0,1 & 2,3 & 3 & Hypopharynx \\
\hline & 1 & 3 & & 3 & Tongue \\
\hline \multirow[t]{4}{*}{ Poorly differentiated } & $0,0,1$ & $2,1,1$ & $2,1,2$ & 3,3 & Tonsils \\
\hline & & & & & Mouth floor or gingival \\
\hline & 1,1 & 0,1 & 1,2 & 2 & Larynx \\
\hline & $1,1,1$ & 0,0 & 2,3 & 3 & Hypopharynx \\
\hline
\end{tabular}

Well-differentiated and moderately differentiated carcinomas are seen to contain significantly more elafin $\left({ }^{*} p<0.0001\right)$ than poorly differentiated carcinomas. Well and moderately differentiated carcinomas also contain significantly higher amounts of SLPI $\left({ }^{*} p<0.0015\right)$ than poorly differentiated carcinomas. The amounts of elastase and IL1-RA do not differ due to the degree of differentiation. The carcinomas were classified as $0,1,2$ and 3 , where 0 represents no positive staining and 3 represents the highest degree of positive staining.

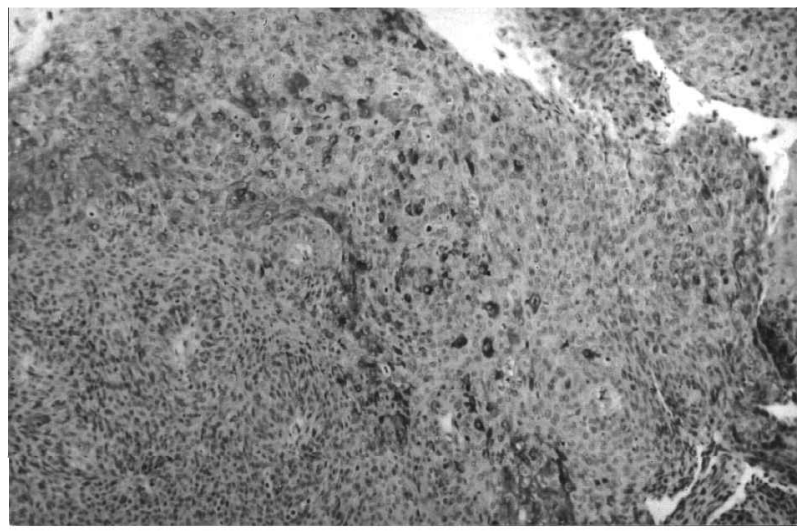

FIG. 1. Well-differentiated carcinoma in tonsils where several metaplastic cells display a positive immunoreaction to elafin $(\times 200)$.

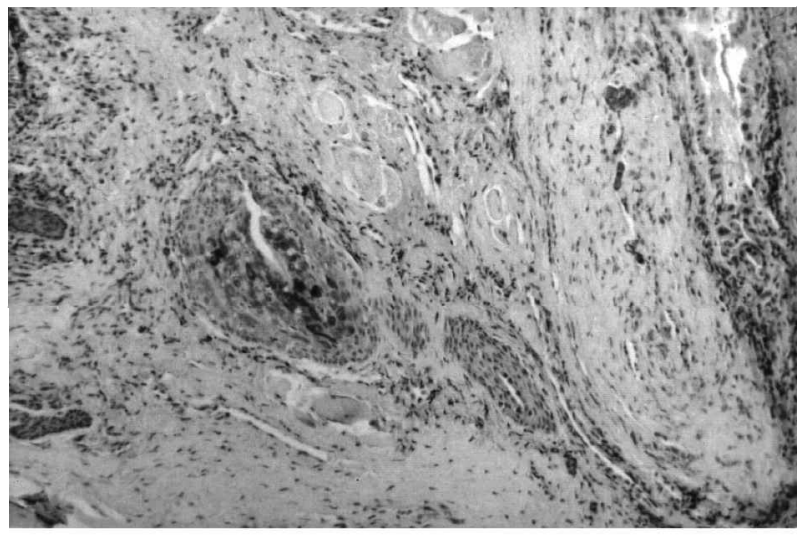

FIG. 3. A section from the same patient as in Fig. 1, showing a positive immunoreaction to IL1-RA in a tumour cell nest $(X$ 200).

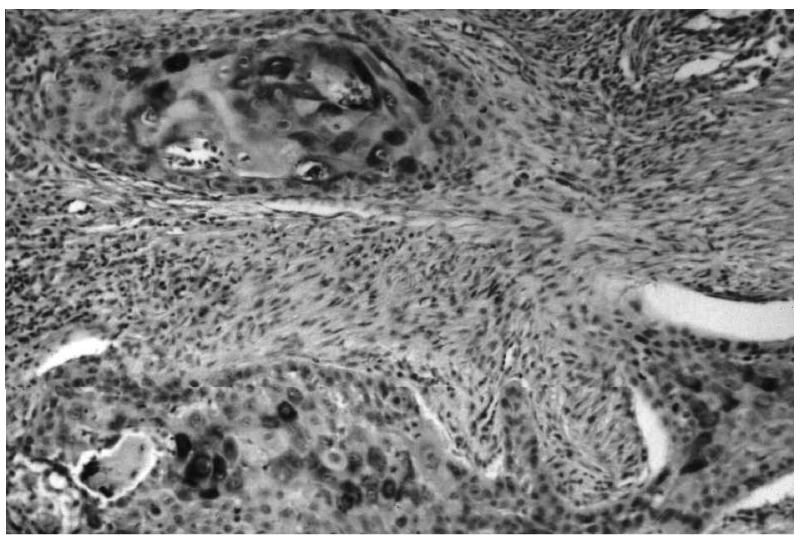

FIG. 2. Well-differentiated carcinoma of the floor of the mouth. Tumour cell nests show distinct positive staining for SLPI $(\times 500)$.

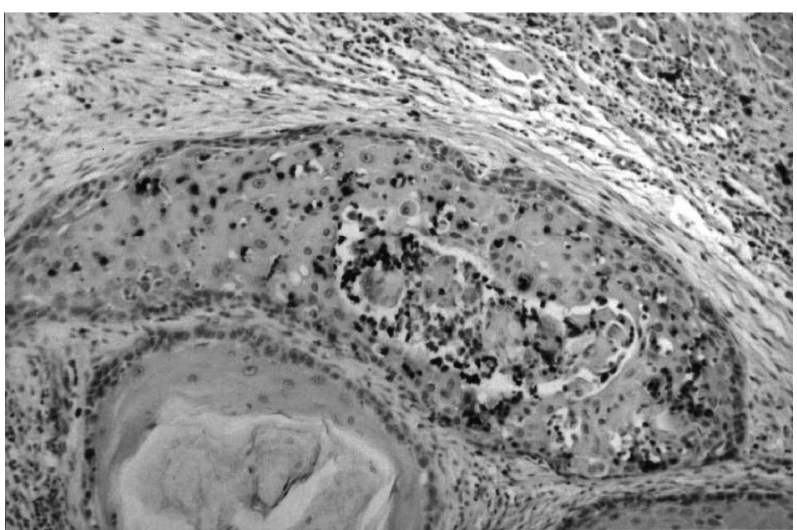

FIG. 4. A section from a carcinoma of the tongue displaying a positive immunoreaction to elastase. Positive elastase staining is seen dispersed in the stroma but with accumulation in the tumour cell nest $(\times 500)$. 


\section{SLPI}

The expression of SLPI was similar to that of elafin except that there seemed to be a smaller amount of SLPI than elafin (Fig. 2). SLPI was expressed at all tumour locations. The amount of SLPI was significantly higher in well-differentiated and moderately differentiated carcinomas than in poorly differentiated carcinomas $(p<0.0015)$ (Table 1$)$.

\section{IL1-RA}

The distribution of IL1-RA coincided with that of SLPI and elafin, but the quantity of IL1-RA did not differ between the degrees of tumour differentiation (Fig. 3).

\section{Elastase}

Elastase was found in various quantities at all tumour locations. The protease was diffusely distributed throughout the tissues, although a slight concentration of elastase was observed close to tumour cell nests (Fig. 4).

\section{$S T N F \alpha R I$}

Sparse amounts of STNF $\alpha$ RI were found in separate tumour cell nests in isolated carcinomas (data not shown).

\section{Moderately differentiated carcinomas}

\section{Elafin}

All but one sample contained elafin-positive tumour cell nests. In areas with poorly differentiated cells, elafin was absent or very sparse.

\section{SLPI}

All but two samples showed positive staining for SLPI. SLPI expression corresponded to that of elafin.

\section{Elastase}

The samples demonstrated the same pattern of expression as in well-differentiated carcinomas.

\section{IL 1-RA}

No differences were seen regarding the amount or location of IL1-RA compared with well-differentiated carcinomas.

\section{$S T N F \alpha R I$}

Some carcinomas contained a few tumour cells with STNF $\alpha$ RI. No difference was demonstrated compared with well-differentiated tumours.

\section{Poorly differentiated carcinomas}

\section{Elafin}

Considerably less tumour cells were positively stained. At some locations, only isolated cells were diffusely spread throughout the tissue. Two of the samples did not contain any elafin at all (Fig. 5A).
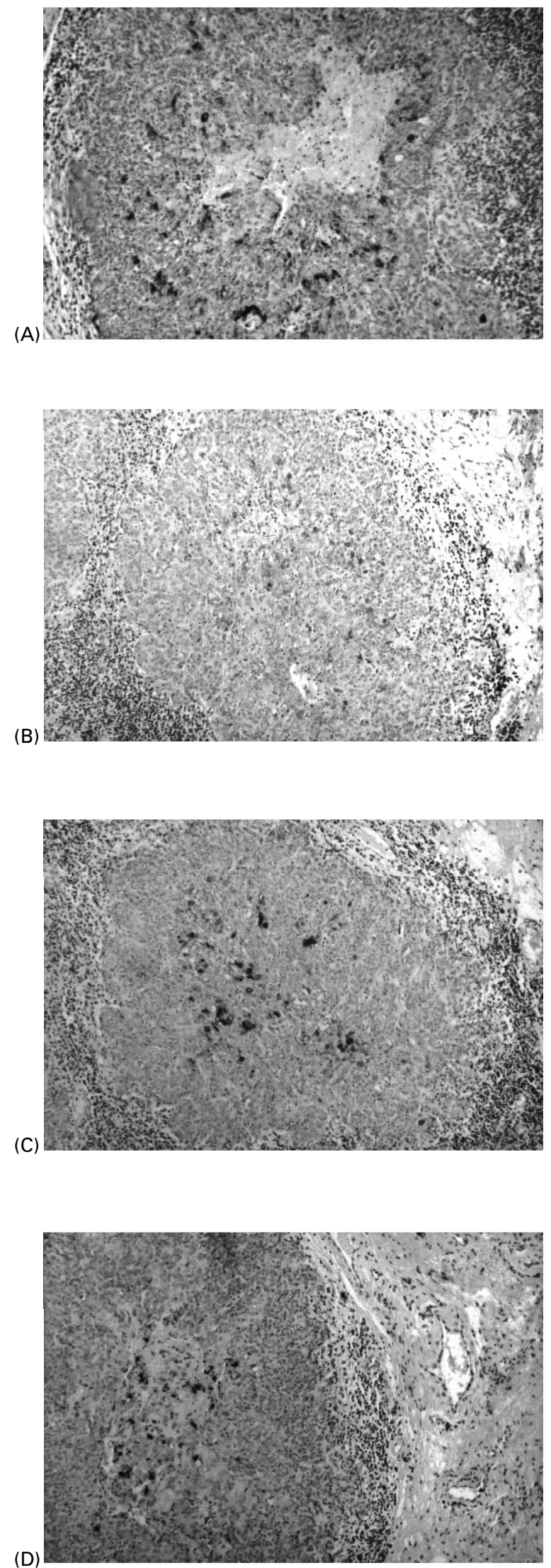

FIG. 5. (A) Poorly differentiated carcinoma of the tonsils. Some of the tumour cells display a positive immunoreaction to elafin in the tumour cell nest, as demonstrated in this section. (B) The same section showing SLPI, (C) the same tumour cell nest showing IL1-RA, and (D) the same tumour cell nest showing elastase $(\times 200)$. 
Table 2. Elafin and SLPI in carcinomas with local lymph node metastases

\begin{tabular}{lcc}
\hline Classification & \multicolumn{2}{c}{ Elafin and SLPI } \\
\cline { 2 - 3 } & 2,3 & 0,1 \\
\hline Lymph node carcinomas & $3(n=8)$ & $7(n=12)$ \\
\hline $\begin{array}{l}\text { Three out of eight patients classified (elafin and SLPI) as } 2 \text { or } 3 \text { had } \\
\text { carcinomas in lymph nodes and seven out of twelve patients } \\
\text { classified as } 0 \text { or } 1 \text { had tumour spread to local lymph nodes. Six } \\
\text { patients out of twenty-six were not TNM classified. }\end{array}$
\end{tabular}

\section{$S L P I$}

SLPI expression followed the same pattern as for elafin. Three samples did not contain any SLPI at all (Fig. 5B).

\section{IL 1-RA}

All carcinomas stained positive for IL1-RA and showed the same pattern of expression as well-differentiated and moderately differentiated tumours (Fig. 5C).

\section{Elastase}

The samples demonstrated the same pattern of expression as in well-differentiated and moderately differentiated carcinomas (Fig. 5D).

\section{$S T N F \alpha R I$}

A small number of carcinomas stained positively in a few tumour cells randomly distributed (data not shown).

\section{Elafin and SLPI in carcinomas with local lymph node metastases}

Three out of eight patients with carcinomas containing SLPI and elafin classified as 3 or 2 had carcinomas in local lymph nodes. Seven out of 12 patients classified as 1 or 0 had tumours spread to local lymph nodes (Table 2).

\section{Discussion}

The presence of protease inhibitors and their target enzymes in tissues indicates an ongoing reaction due to hostile agents in order to protect the host. The maintenance of protease/protease inhibitor balance is of vital importance in protecting against extensive tissue destruction. This balance is also sustained in cancer. One could argue that leukocyte invasion and degranulation in tumours probably protects the host from malignant cells. A side-effect of proteolytic activity is degradation of surrounding tissue, which could enhance tumour spread. Therefore, it is important that a relevant local inhibitor is available. Another important function could be as an inhibitor of the cell cycle, which has been demonstrated in mammary epithelial cells and carcinomas by the down-regulation of elafin mRNA in S-phase in normal cells. ${ }^{19}$
IL-1 $\beta$ and TNF $\alpha$ are cytokines known to participate in protein induction. SLPI and elafin have been shown to be generated by these cytokines. ${ }^{9,21}$ To overcome the difficulties in detection of these substances due to the small amounts present in tissues, we studied their inhibitors (IL1-RA and STNF $\alpha$ RI) instead, which are usually found in excess and are easier to detect.

All sterile tissue is devoid of elafin. Epithelial tissue subjected to constant inflammatory stimuli, such as the oral cavity or genital tract, contains elafin. Elafin is not present in normal skin, whereas keratinocytes in psoriatic scales produce the inhibitor. ${ }^{1,12}$ SLPI, which is expressed in serous cells of the mucosa of the respiratory tract and in several other glandular epithelia, has been shown to be inducible in keratinocytes. $^{10,11,23}$ Both these inhibitors probably offer protection against activated leukocyte-induced and elastase-induced cell detachment, which could protect against tumour invasion in adjacent tissue.

The locations of SLPI and elafin in squamous cell carcinomas coincide, although slightly less SLPI is present than elafin. The amounts of these inhibitors are correlated to the degree of tumour differentiation. Well-differentiated and moderately differentiated carcinomas contain more SLPI and elafin than poorly differentiated carcinomas. Positive staining was seen in cells with distinct squamous differentiation. In moderately differentiated carcinomas, only well-differentiated cells demonstrated SLPI and elafin. Poorly differentiated cells did not stain positively for either of the inhibitors.

Since there was no difference between elastase presence in well-differentiated, moderately differentiated and poorly differentiated tumours, one might assume that protection against cell detachment, and hence tumour spread, is inferior in poorly differentiated carcinomas. It seems that even poorly differentiated carcinomas were able to produce IL1RA. It appears that although poorly differentiated cells are able to express IL1-RA, only well-differentiated tumour cells can respond and produce SLPI and elafin. The same is true of elastase, which also stimulates their production. ${ }^{9}$ STNF $\alpha$ RI was only found in isolated tumour cells, which could be attributed to the immunohistological techniques available at our laboratory.

There are many chemical processes that contribute to cancer development and spread. Protection against cell detachment might be one mechanism against cancer progression. Patients with poorly differentiated tumours and low amounts of or no inhibitors had developed lymph node metastase to a higher degree than the other patients.

In conclusion, the ability to produce SLPI and elafin coincided with well-differentiated tumours and with less spread to local lymph nodes at the time of diagnosis. A clinical implication of these results could be that the expression of these inhibitors could be 
used as a prognostic tool and maybe predict the outcome of the disease.

ACKNOWLEDGEMENTS. This project was supported by grants from The Swedish Medical Research Council (grant number 03910), the Medical Faculty University of Lund, the Foundations of Alfred Österlund and the University Hospital of Malmoe.

\section{References}

1. Schalkwijk J, Chang A, Janssen P, De Jongh GJ, Mier PD. Skin-derived antileucoproteases (SKALPs): characterization of two new elastase inhibitors from psoriatic epidermis. $\mathrm{Br} J$ Dermatol 1990; 122: 631-641.

2. Molhuizen HO, Alkemade HA, Zeeuwen PL, De Jongh GJ, Wieringa B, Schalkwijk J. SKALP/elafin: an elastase inhibitor from cultured human keratinocytes. Purification, cDNA sequence, and evidence for transglutaminase cross-linking. J Biol Chem 1993; 268: 12028-12032.

3. Fryksmark U, Ohlsson K, Rosengren M, Tegner H. Studies on the interaction between leukocyte elastase, antileukoproteinase and the plasma proteinase inhibitors alpha 1-proteinase inhibitor and alpha 2-macroglobulin. Hoppe Seylers Z Physiol Chem 1983; 364: 793-800.

4. Thompson RC, Ohlsson $\mathrm{K}$. Isolation properties, and complete aminoacid sequence of human secretory leukocyte protease inhibitor of leukocyte elastase. Proc Natl Acad Sci USA 1986; 83: 6692-6696.

5. Carmichael DF, Ohlsson K. Chemistry and biology of secretory leukocyte protease inhibitor. In: Crystal RG, ed. $\alpha_{1}$-Antitrypsin Deficiency. Biology. Pathogenesis. Clinical Manifestations. Therapy. New York: Marcel Dekker, 1996: 193-208.

6. Gauthier F, Fryksmark U, Ohlsson K, Bieth JG. Kinetics of the inhibition of leukocyte elastase by the bronchial inhibitor. Biochim Biophys Acta 1982; 700: 178-183.

7. Axelsson L, Linder C, Ohlsson K, Rosengren M. The effect of the secretory leukocyte protease inhibitor on leukocyte proteases released during phagocytosis. Biol Chem Hoppe Seyler 1988; 369 (Suppl): 89-93.

8. Wiedow $O$, Luademann $J$, Utecht $B$, Elafin is a potent inhibitor of proteinase 3. Biochem Biophys Res Commun 1991; 174: 6-10.

9. Sallenave JM, Shulmann J, Crossley J, Jordana M, Gauldie J. Regulation of secretory leukocyte proteinase inhibitor (SLPI) and elastase-specific inhibitor (ESI/elafin) in human airway epithelial cells by cytokines and neutrophilic enzymes. Am J Respir Cell Mol Biol 1994; 11: 733-741.

10. Fryksmark U, Ohlsson K, Polling A, Tegner H. Distribution of antileukoprotease in upper respiratory mucosa. Ann Otol Rbinol Laryngol 1982; 91 (3 Part 1): 268-271.
11. Westin U, Fryksmark U, Polling Å, Ohlsson K. Localisation of secretory leucocyte proteinase inhibitor mRNA in nasal mucosa. Acta Otolaryngol 1994; 114: 199-202.

12. Pfundt $R$, van Ruissen F, van Vlijmen-Willems IM, Alkemade HA, Zeeuwen PL, Jap PH, Dijkman H, Fransen J, Croes H, van Erp PE, Schalkwijk J. Constitutive and inducible expression of SKALP/elafin provides antielastase defense in human epithelia. J Clin Invest 1996; 98:1389-1399.

13. Travis J, Salvesen GS. Human plasma proteinase inhibitors. Annu Rev Biochem 1983; 52: 655-709.

14. Liotta LA. Tumor invasion and metastases - role of the extracellular matrix: Rhoads Memorial Award lecture. Cancer Res 1986; 46: 1-7.

15. Liotta LA, Steeg PS, Stetler-Stevenson WG. Cancer metastasis and angiogenesis: an imbalance of positive and negative regulation. Cell $1991 ; 64: 327-336$

16. Janoff A. Elastase in tissue injury. Annu Rev Med 1985; 36: 207-216.

17. Ohlsson $\mathrm{K}$, Tegner $\mathrm{H}$. Inhibition of elastase from granulocytes by the low molecular weight bronchial protease inhibitor. Scand J Clin Lab Invest 1976; 36: 437-445.

18. Amiguet JA, Jimenez J, Monreal JI, Hernandez MJ, Lopez-Vivanco G, Vidan JR, Conchillo F, Liso P. Serum proteolytic activities and antiproteases in human colorectal carcinoma. J Physiol Biochem 1998; 54: 9-13.

19. Zhang M, Zou Z, Maass N, Sager R. Differential expression of elafin in human normal mammary epithelial cells and carcinomas is regulated at the transcriptional level. Cancer Res 1995; 55: 2537-2541.

20. Amiguet JA, Jimenez J, Monreal JI, Hernandez MJ, Lopez-Vivanco G, Vidan JR, Conchillo FA, Liso P. SKALP/elafin is an inducible proteinase inhibitor in human epidermal keratinocytes. J Cell Sci 1994; 107 (Part 8): 2335-2342.

21. Pfundt R, Wingens M, Bergers M, Zweers M, Frenken M, Schalkwijk J. TNF-alpha and serum induce SKALP/elafin gene expression in human keratinocytes by a p38 MAP kinase-dependent pathway. Arch Dermatol Res 2000; 292: 180-187.

22. van Wetering S, van der Linden AC, van Sterkenburg MA, de Boer WI, Kuijpers AL, Schalkwijk J, Hiemstra PS. Regulation of secretory leukocyte proteinase inhibitor (SLPI) production by human bronchial epithelial cells: increase of cell-associated SLPI by neutrophil elastase. $J$ Investig Med 2000; 48: 359-366.

23. Wingens M, van Bergen BH, Hiemstra PS, Meis JF, van Vlijmen-Willems IM, Zeeuwen PL, Mulder J, Kramps HA, van Ruissen F, Schalkwijk J. Induction of SLPI (ALP/HUSI-I) in epidermal keratinocytes. I Invest Dermatol 1998; 111 : 996-1002.

Received 23 August 2001

Accepted 16 October 2001 


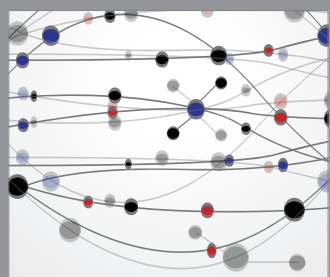

The Scientific World Journal
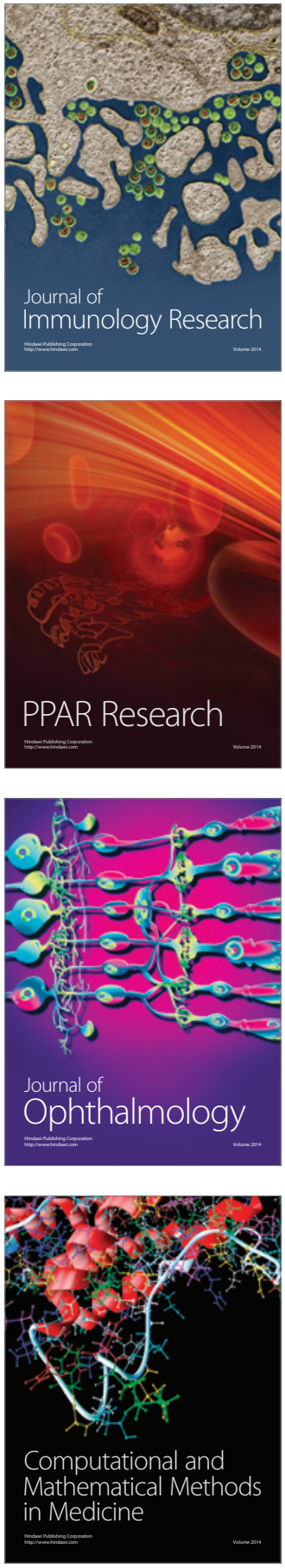

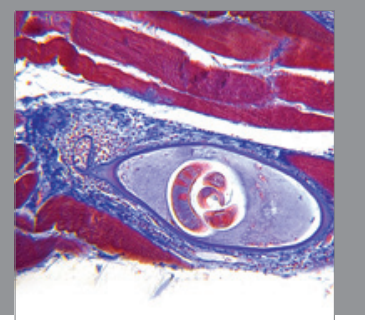

Gastroenterology

Research and Practice
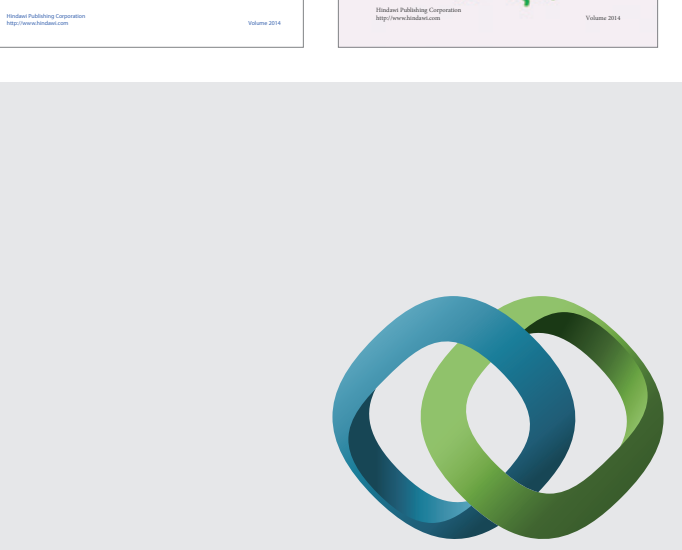

\section{Hindawi}

Submit your manuscripts at

http://www.hindawi.com
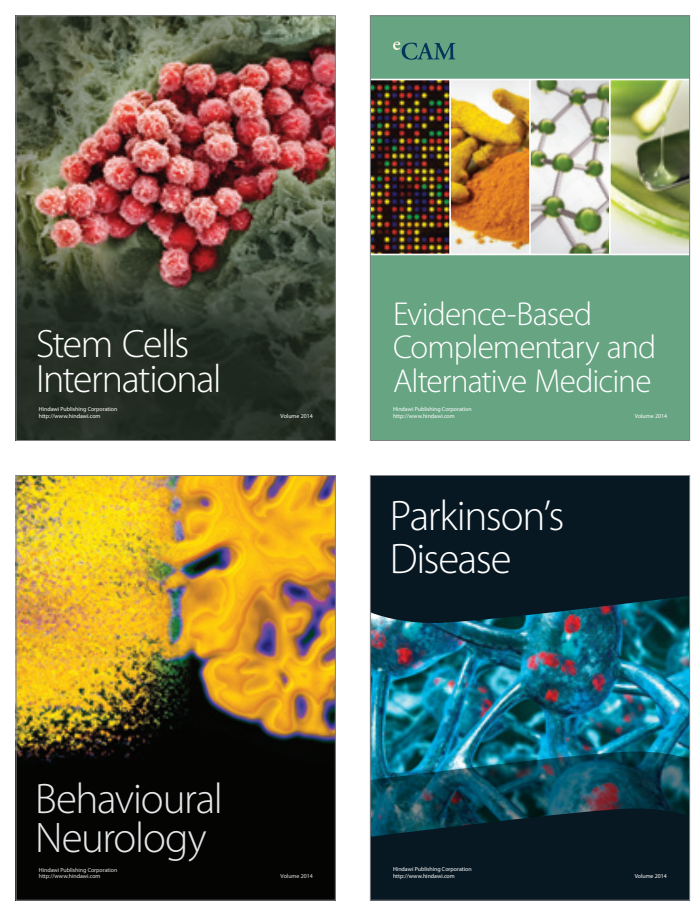

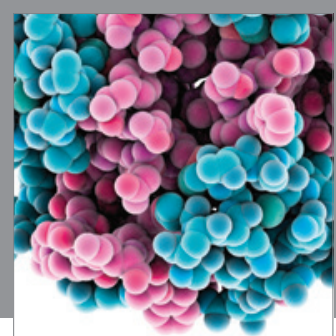

Journal of
Diabetes Research

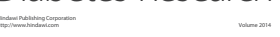

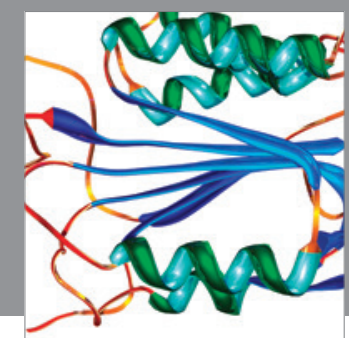

Disease Markers
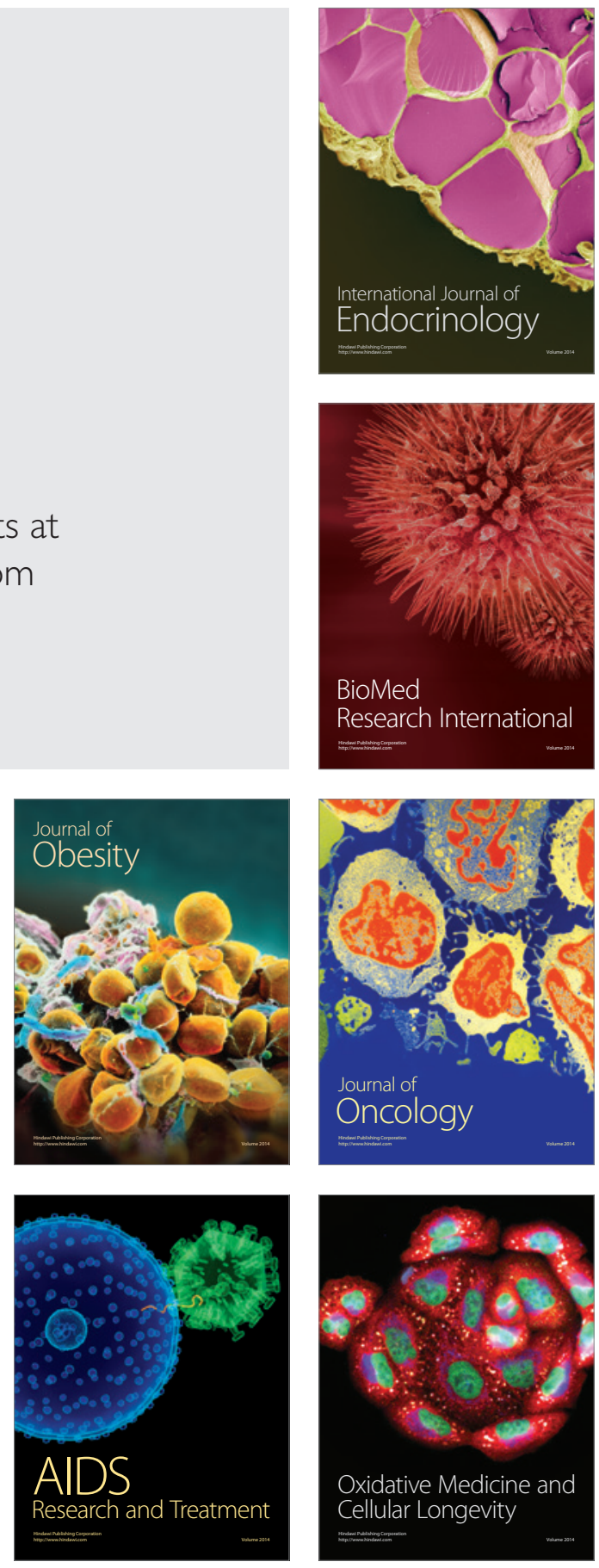